\title{
RECONSIDERANDO GRAMSCI: HEGEMONIA NO DIREITO GLOBAL
}

\author{
Sonja Buckel e Andreas Fischer-Lescano
}

GRAMSCI RECONSIDERED: HEGEMONY IN GLOBAL LAW

TRADUção Tatiane Honório Lima

\section{RESUMO}

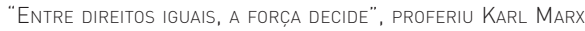
AO DESCREVER A ANTINOMIA DO DIREITO EM SITUAÇÕES ANTAGÔNICAS DAS RELAC̣ÕES DE PRODUÇÃO CAPITALISTAS, EM QUE "O DIREITO [OFERECE RESISTÊNCIA] AO DIREITO". 1 NESSE PONTO, MARX ABORDA UMA QUESTÃO QUE SE SITUA NO CENTRO DE TODAS AS TEORIAS JURÍDICAS CRITIICAS: QUE TIPO DE VIOLÊNCIA É VELADA POR MEIO DO MECANISMO DE OCULTAÇÃO DENOMINADO "DIREITO"?

PARA RESPONDER A ESTA QUESTÃo, TENTAR-SE-Á, A SEGUIR, TORNAR a teoria da hegemonia de ANTONIO GRamsci e SEU modelo DE DIREITO HEGEMÔNICO PRODUTIVOS PARA O CAMPO DA TEORIA DO DIREITO. TAL TAREFA TEM DE LIDAR COM A DUPLA DIFICULDADE DE QUE, POR UM LADO, GRAMSCI NÃO FOI UM TEÓRICO DO DIREITO NO SENTIDO MAIS ESTRITO, RAZÃO PELA QUAL O POTENCIAL DE SUA TEORIA PARA UMA ANÁLISE DO DIREITO RARAMENTE FOI UTILIZADA. ${ }^{2}$ POR OUTRO LADO, SUA ABORDAGEM SÓ PODE SER EMPREGADA POR MEIO DE UMA CRÍTICA ÀS RESTRIÇÕES RELACIONADAS A SEU TEMPO. ISSO SE APLICA ESPECIALMENTE À SUA CONCEPCC̄O DE ECONOMIA COMO A BASE E A NÚCLEO ESSENCIALISTA OCULTO (LACLAU; MOUfFe, 2001:69), ASSIM COMO À SUA IDEIA DE 'CLASSISMO' SOB A FORMA DE UM ENFOQUE UNILATERAL DAS CLASSES, EM QUE HÁ PREFERENCIALMENTE MAIS DE UM "PLURALISMO DE PODER" E INÚMERAS LUTAS (LITOWITZ, 2000: 536). RECUPERARSE-Á, CONSEQUENTEMENTE, ARGUMENTOS-CHAVE, AMPLIANDO-OS PELA UTILIZAÇÃO DAS RECENTES DESCOBERTAS FEITAS PELAS ABORDAGENS FEMINISTA E NEOMATERIALISTA DA TEORIA JURÍDICA, BEM COMO AS ANÁLISES DE FOUCAULT ACERCA DAS TECNOLOGIAS DE PODER. POR FIM, UMA INTERPRETAÇÃO DA TEORIA SISTÊMICA DAS AUTONOMIZAÇÕES COMUNICATIVAS.

\section{PALAVRAS-CHAVE}

GRAMISCI; TEORIA DA HEGEMONIA; TEORIA DO DIREITO; DIREITO GLOBAL

\section{ABSTRACT}

"BETWEen EQUAL RIGHTS, ForCE DECIDES," SAID KarL MARX, DESCRIBING THE ANTINOMY OF LAW IN ANTAGONISTIC SITUATIONS OF CAPITALIST PRODUCTION RELATIONS, IN WHICH "LAW [STANDS] AGAINST LAW". HE HERE ADDRESSES A QUESTION THAT LIES AT THE CENTRE OF ALL CRITICAL LEGAL THEORIES: WHAT VIOLENCE IS BLURRED IN THE MEDIUM OF THE CONCEALMENT MECHANISM CALLED 'LAW'?

TO ANSWER THIS QUESTION, WE SHALL ATTEMPT BELOW TO MAKE ANTONIO GRAMSCI'S HEGEMONY THEORY AND HIS MODEL OF A HEGEMONIC LAW FERTILE FOR THE THEORY OF LAW. THIS TASK HAS TO COPE WITH THE TWOFOLD DIFFICULTY THAT ON THE ONE HAND GRAMSCI WAS NO THEORETICIAN OF LAW IN THE NARROWER SENSE, WHICH IS WHY THE POTENTIAL OF HIS THEORY FOR AN ANALYSIS OF LAW HAS ONLY SELDOM BEEN MADE USE OF. ON THE OTHER, HIS APPROACH CAN ONLY BE TAKEN UP THROUGH A CRITIQUE OF RESTRICTIONS ASSOCIATED WITH HIS TIMES. THIS APPLIES PARTICULARLY TO HIS CONCEPTION OF THE ECONOMY AS THE BASIS AND AS THE CONCEALED ESSENTIALIST CORE (LACLAU/MOUFFE 2001 69), AS WELL AS TO HIS 'CLASSISM' IN THE FORM OF A ONESIDED FOCUSING ON CLASSES, WHERE THERE IS INSTEAD MORE OF A "PLURALISM OF POWER" AND A MULTIPLICITY OF STRUGGLES (LITOWITZ 2000: 536). WE SHALL ACCORDINGLY REGAIN KEY ARGUMENTS BY EXTENDING THEM USING CURRENT FINDINGS OF FEMINIST AND NEO-MATERIALIST APPROACHES TO LEGAL THEORY, AS WELL AS FOUCAULT'S ANALYSES OF POWER TECHNOLOGIES AND FINALLY A SYSTEMS-THEORY INTERPRETATION OF COMMUNICATIVE AUTONOMIZATIONS.

\section{KEYWORDS}

GRAMISCI; HEGEMONY THEORY; THEORY OF LAW; GLOBAL LAW 
teoria da hegemonia de Gramsci pode oferecer uma contribuição inovadora ao debate sobre a presença de questões políticas no direito, debate esse que tem acompanhado o direito moderno desde seu aparecimento, estendendose tanto às principais teorias filosófico-sociais como à teoria da "metodologia" jurídica. Enquanto a tradição kantiana considera o aspecto político em uma ligação peculiar do direito a um aparelho de sanção democraticamente legitimado, e prevaleça certa unanimidade - de Kelsen a Habermas - no que se refere à necessária identificação do direito e do Estado como poderes punitivos, teóricos pós-modernos, desde Michel Foucault até Jacques Derrida, bem como feministas, tais como Catharine MacKinnon, tentaram medir as profundezas míticas dessa unidade de Estado e direito. ${ }^{3}$ Ao passo que a tradição kantiana almeja controlar a força, conformando as políticas de Estado enquanto “teoria jurídica aplicada” (KANT, 1795:202), a corrente pós-moderna vê no centro do direito o próprio fenômeno que a tradição jurídica kantiana procura pacificar por todos os meios fornecidos pelo direito: a premissa do direito como um ato de violência sem fundamento (DERRIDA, 1990:924). Os fenômenos de violência assim identificados visam a objetivos mais densos do que a ligação do conceito estadista de direito a um aparelho policial e militar de coerção. Eles visam, antes, à "totalidade do direito" e a uma violência sutil: a forma violenta da legislação, as contingências de cada decisão jurídica que separa o legal do ilícito e prefere uma das duas posições legais antagonistas a outra. Tal enfoque torna as contradições sociais, enquanto motor principal da dinâmica social, o tema essencial da teoria jurídica, que agora observa os complicados processos de tradução nos quais as contradições sociais são transformadas em conflitos jurídicos que podem, cada vez mais, apenas ser descritos como confrontos de massas globais de direito no âmbito de um "direito global sem um Estado global" (FISHER-LESCANO; TEUBNER, 2004:999; BECKER, 2005; KOSKENNIEMI, 2005).

Contudo, a presença de questões políticas também é investigada pelas teorias críticas no cerne da autodescrição jurídica, na metodologia, visto que abordam a questão referente ao modo como as relações de poder social são convertidas em direito e como estas influenciam as decisões jurídicas: na teoria metodizadora de direito privado, por exemplo, a partir da escola histórica em torno da figura de Friedrich Carl von Savigny (1779-1861), até a jurisprudência 'conceitual' e de 'interesses', ou, ainda, no "formalismo jurídico" americano, a opinião ainda predominante era a de que as decisões jurídicas seguem uma lógica formal, racional ou, no mínimo, de aplicação da lei. Isso foi contestado tanto pela Escola do Direito Livre quanto pelo movimento de "realismo jurídico" e de "Estudos Críticos do Direito" (Critical Legal Studies - CLS), todos insistindo no caráter político presente em cada decisão jurídica. O próprio fato de a prática jurídica acreditar que possa, "sem qualquer base teórico-jurídica ou sócio-filosófica explícita, limitar-se ao status de "metodologias "neutras'” a transforma em “jurisprudência política” em sentido genuíno (WIETHÖLTER, 1977: 235 f.), visto 
que não poderia sequer perceber o quão pouco havia recorrido a métodos doutrinários de decisões judiciais, e em que medida, por outro lado, transmite uma determinado "pré-conceito" internalizado (ESSER, 1970: 7-10). Considerados de maneira mais rigorosa, os juízes não aplicam a lei, mas a fazem e, assim, operam "politicamente”, não “juridicamente” (WIETHÖLTER, 1968: 292). Nesse processo de "legislação judicial”, projetos ideológicos são encaminhados (KENNEDY, 1997: 1), de modo que o direito passa a ser nada mais do que "mera política numa roupagem diferente" (HUTCHINSON; MONAHAN, 1984: 206), cujos resultados não são nada previsíveis, sendo, antes, profundamente "indeterminados". Por conseguinte, o tópos central do CLS tornou-se a "indeterminação" do direito (a esse respeito, ver Frankenberg, 2006: 104). Ingeborg Maus salienta que tal indeterminação possui causas sociais, isto é, uma técnica legislativa que funciona devido a conflitos politicamente não resolvidos, com cláusulas gerais. Isso leva ao fato de que "todos os aparelhos governamentais, por si só, assumem o trabalho de legislatura sob condições específicas de aplicação da lei, enquanto que, em uma época tomada por uma inundação crescente de normas, o caráter obrigatório da lei se enfraquece sob uma aparência legitimadora” (1992: 294). Por outro lado, abordagens com base na teoria sistêmica consideram tal conjuntura uma característica intrínseca do ordenamento jurídico, que deve ser entendida de maneira mais fundamental, como "indecibilidade" (TEUBNER, 1993). Uma expressão do caráter paradoxal do sistema jurídico (LUHMANN, 2004: 381) refere-se ao fato de que, na comunicação jurídica, não se pode inquirir se a distinção entre certo e errado existe correta ou incorretamente. Em vez disso, essas situações paradoxais, as quais se tornam meramente invisíveis por meio da dogmática, revelam o "discurso monótono da hegemonia” (FISCHER-LESCANO; CHRISTENSEN, 2005: 220, 234).

Por mais plausível que essa crítica da ideologia seja, esta depende, contudo, de uma teoria da ideologia, i.e. de uma teoria que questione as condições constitutivas da ideologia. Como surge o impenetrável pré-conceito jurídico? De que forma as decisões jurídicas podem ser consideradas "políticas" ou "ideológicas"? E, por fim: qual é o "valor agregado" do Direito, caso a ideologia apareça em sua forma pura? Tais questões serão respondidas apresentando, primeiramente, a teoria da hegemonia de Antonio Gramsci para, então, aplicá-la ao Direito. Por último, apresentaremos algumas considerações acerca das técnicas contra-hegemônicas que contemplam uma transformação democrática do direito global.

\section{A Autonomia do ideológico: A teoria da hegemonia de Gramsci}

Gramsci, juntamente com Georg (Gyögy) Lukács, foi um dos primeiros teóricos marxistas a atentar explicita e sistematicamente, no final da década de 1920, aos chamados fenômenos de "superestrutura". Contra o marxismo economicista, ele insistiu na materialidade das "ideologias": "elas não são de forma alguma ilusão e aparência," 
mas sim "uma realidade operante e objetiva” (GRAMSCI, 1991 ff., Q4§15: 475). No terreno das ideologias, as pessoas alcançam a consciência dos conflitos sociais fundamentais (ibid. §38: 502) e, consequentemente, elaboram sua relação com o mundo pelas ideologias (BUCI-GLUCKSMANN 1980: 60). É com Gramsci que a transição teórica fundamental é efetuada, partindo do conceito de ideologia entendido enquanto "sistemas de ideias", sendo, portanto, mero espelhamento sem realidade específica, e chegando à ideia de ideologia entendida como "prática social viva e habitual” (EAGLETON, 1991: 115). A ideologia materializa-se em instituições e praxes - devemos ainda acrescentar que a ideologia, tendo em vista Foucault e Bordieu, materializa-se também em subjetividades - o que não é "uma afirmação pequena a respeito da realidade” (GRAMSCI, ibid.). Apesar de Gramsci manter os conceitos de "superestruturas", Laclau/Mouffe consideram, no entanto, que sua teoria exclui a interpretação do ideológico enquanto "falsa consciência" (2001: 67): se a ideologia goza do poder de realidade tanto quanto os processos econômicos, consequentemente uma distinção hierárquica entre "estrutura" e "superestrutura" dificilmente pode continuar a ser mantida. Devemos acrescentar, contudo, que a separação de setores sociais com sua própria dinâmica intrínseca já é, por si só, resultado histórico da divisão capitalista do trabalho, aqui referente particularmente àquela divisão existente entre trabalho intelectual e manual (Poulantzas 2001: 54 ff.), e que, nesse sentido, "a realidade social, em sua estrutura produtiva (certamente) produz ideologias" (GRAMSCI ibid. §15: 475).

A realidade efetivamente poderosa da ideologia nas instituições e no modo como a vida é conduzida (DEMIROVIC, 1999: 21) possui um significado proeminente para uma teoria jurídica. Pois o direito, assim como a moralidade, a religião ou a cultura, encontra-se em sua totalidade na esfera do ideológico. Por conseguinte, não é meramente "infectado" pela ideologia, como exposto no debate crítico metodológico, mas é, em vez disso, seguindo o teórico político franco-grego de inspiração gramsciana Nico Poulantzas (2001: 80), a instituição ideológica unificante nas sociedades capitalistas, substituindo a religião, ideologia dominante do feudalismo.

Gramsci atribuiu grande valor à autonomia do ideológico, considerando-a um importante espaço de conflitos. Embora a luta da classe trabalhadora nas fábricas não tenha sido suficiente, ela deve, sim, ser expandida à área das "superestruturas". Isso ampliou o campo da hegemonia, uma vez que o aspecto especial da teoria da ideologia gramsciana é o fato de que a categoria-chave nos escritos de Gramsci não é a "ideologia", mas a "hegemonia" (EAGLETON, 1991: 112). Ao usar tal categoria, ele rejeitou uma concepção mecanicista acerca do surgimento da "consciência de classe”, i.e. o reflexo ideológico do indivíduo acerca de seu próprio lugar na sociedade. Essa consciência não surgiu espontaneamente da posição "objetiva” de um grupo social, o qual, pelo contrário, poderia produzir apenas uma consciência "sindicalista”, ou seja, uma autopercepção direta e com base no status (GRAMSCI, 1991 
ff., Q4§38: 495). Apenas uma única vez um agrupamento social iniciou uma luta mais complexa acerca das superestruturas (ibid. 496), superando seus próprios interesses "corporativos" e se orientado em direção a um processo de "catarse" a partir do qual surgira uma consciência da necessidade de levar outros interesses em consideração e, portanto, universalizar a posição particularista. Nesse contexto, poder-se-ia falar na fase "ético-política" no cerne da relação das forças políticas. A hegemonia é um processo contraditório de generalização, processo esse que deve abranger todas as áreas da atividade humana, permitindo a liderança social - ou seja, uma liderança não apenas econômica, mas também de cunho político e ideológico (PRIESTER, 1981: 38; SASSOON, 1987: 118). Ela pressupõe tanto concessões àqueles sobre os quais a hegemonia é exercida, num equilibro assimétrico de compromisso (GRAMSCI, 1991 ff., Q13§18: 1567), como a capacidade de desenvolver uma "visão de mundo" por meio da qual os governados possam ser conduzidos (H 6§10: 719). Somente desta forma pode-se garantir o consenso entre tais indivíduos (ibid. §13: 721).

Gramsci se opôs a uma teoria mecanicista do poder. Assim como Foucault, ele considerou que, em sociedades burguesas modernas, o governo não mais poderia acontecer via "imperativo da obediência", que a "obediência" não poderia ser entendida automaticamente ou como resultado de algum "mecanismo pequeno e simples" (FOUCAULT, 1990: 81). A obediência originou-se não a partir de si mesma, mas de uma prova necessariamente ideológica de sua "necessidade" ou "racionalidade" (GRAMSCI, 1991 ff., Q15§4, 714). O ponto decisivo para o grupo hegemônico foi apresentar uma autopercepção teórica, uma "filosofia", a qual não deveria ser apenas a posse exclusiva de um estrato restrito de intelectuais, mas que teria de se tornar uma weltanschauung (visão de mundo), manifestada implicitamente pela arte, pela economia, pela política e, especificamente, também pelo direito, em todas as expressões “moleculares" e coletivas da vida (KRAMER, 1975: 95; GRAMSCI, 1991 ff., Q17§ 51: 1890).

A hegemonia é, portanto, uma forma particular de vida e pensamento, uma weltanschauung, em que se baseiam as preferências, o gosto, a moralidade, a ética e os princípios filosóficos da maioria na sociedade (KRAMER, ibid. 90). Dessa forma, o conceito exprime mais do que a legitimidade weberiana (BUCI-GLUCKSMANN, 1980: 56), ou seja, o controle por meio de um consenso assimétrico disseminado por toda a estrutura da vida social e que, portanto, se "naturaliza" na forma de costume, hábito e prática espontânea (EAGLETON, 1991: 116). Isso é uma espécie sutil de poder que se tornou o senso comum de toda uma ordem social (ibid. 114). Mas tal conceito não deve ser compreendido como "colonização do mundo interior" (cf. e.g. LITOWITZ, 2000: 523), pois a hegemonia não é um tema metafísico, mas uma prática permanente, uma visão de mundo disputada em lutas por reconhecimento, por meio da qual a liderança moral, política e intelectual é estabelecida. 
Muito antes do conceito foucaultiano de "governamentalidade", usado para descrever a "arte de governar" no sentido de controle diário da conduta e da regulação de autotecnologias (FOUCAULT, 2004: 241), Gramsci já insistia que "de fato existiam governados e governantes, líderes e liderados” (GRAMSCI, 1991 ff., Q 16§4: 1713). A política e toda a ciência política basearam-se nesse fato fundamental, a arte de "como alguém pode governar de forma mais eficaz [...] e, por outro lado, reconhecer a linha de menor resistência [...], a fim de assegurar a obediência dos liderados ou governados (Ibid.). Aqui, a ideia de "governo" é fundamentalmente diferente da noção cotidiana de "governo em sentido técnico" (Q17§51, 1890).

Contudo, líderes e liderados não podem mais, de acordo com a teoria de Gramsci, ser identificados com uma classe "dominante" ou dominada. Não porque, por assim dizer, as classes não existam mais, mas porque o policentrismo das relações modernas de poder social se baseia em situações específicas (para subsistemas) de controle e exploração, entrelaçadas a uma pluralidade de diversas tecnologias de poder, e se constituem juntamente com elas. Aqui, com esses mesmos conceitos de "relações de força" (sobre estes, ver WISSEL, 2007) e de "hegemonia", Gramsci oferece uma possibilidade de superação das limitações históricas do classismo. Dessa forma, como indicado por Laclau/Mouffe, os sujeitos coletivos, para Gramsci, não são classes propriamente ditas, mas "vontades coletivas" complexas, resultado ou síntese maior da articulação político-ideológica de forças históricas dispersas e fragmentadas (2001:68). Tomando o conceito de "interseccionalidade" da teoria jurídica feminista (cf. ELSUNI, 2006: 180 f.), é possível observar o "bloco hegemônico" de Gramsci de forma mais multidimensional, como um sistema de aliança de posições de sujeito dominantes estabilizadas ao longo de um determinado período: "Em vez disso, os indivíduos são vistos como pontos de intersecção, em que múltiplos eixos mutuamente perpendiculares de desvantagens se encontram. Sendo, via de regra, desfavorecidos em alguns eixos e, ao mesmo tempo, favorecidos em outros, no regime moderno tais indivíduos visam a lutas por reconhecimento". (FRASER, 2003: 80).

A weltanschauung desse sistema de alianças constituído por uma pluralidade de atores e o efeito geral do qual escapam suas praxes estratégicas é inscrito, nesse sentido, nas instituições, praxes e temas e, portanto, também no direito. E aqui Gramsci preocupava-se em enfatizar que nem todas as forças sociais apresentam chances iguais para se tornarem hegemônicas. A herança das lutas passadas é uma seletividade estratégica estruturalmente inscrita que favorece algumas lutas em detrimento de outras (JESSOP, 1990: 309).

\section{Aparelhos de hegemonia}

Se a prática ideológica deve ser entendida enquanto algo material e institucional, então essa materialidade precisa ser analisada de forma mais rigorosa. Gramsci 
empenha-se em compreendê-la pelo conceito de "aparelho de hegemonia" (1992 ff., Q6§87: 782): como uma unificação da hegemonia num "aparelho" (BUCIGLUCKSMANN, 1980: 48), isto é, uma consolidação institucional, interessada na autopreservação de forma organizada, que exibe autonomia relacional vis-à-vis a relações sociais de poder. Ele considera que os aparelhos de hegemonia decisivos são aqueles da "sociedade civil", ou seja, escolas, universidades, igrejas, meios de comunicação de massa, sindicatos etc. Uma inovação introduzida por Gramsci nesse momento é a realocação do termo "sociedade civil”. Este não mais denota um público anti ou não governamental, mas, sim, o conjunto de todos os aparelhos de hegemonia comumente denominados "privados". E, ao mesmo tempo, tal termo forma, juntamente com o Estado no sentido mais restrito, o "Estado integral" e, assim, os dois maiores níveis superestruturais que combinam hegemonia e controle direto: "ditadura mais hegemonia" ou "hegemonia blindada com coerção" (Q6§155: 824; §88: 783). Eles organizam um consenso e, também, na eventual ocorrência de uma crise de liderança no aparelho governamental de coerção, providenciam a disciplina dos dissidentes ativos ou passivos (Q12§1: 1502).

Mesmo se a separação aparentemente rigorosa das duas áreas superestruturais em uma área hegemônica e outra repressiva for, acima de tudo, uma separação metodológica (PRIESTER, 1981: 60) ou de cunho mais enfático do que de essência (SASSOON, 1987: 113), e, além disso, Louis Althusser estiver certo sobre a ideia de que o Estado ampliado consiste em vários aparelhos, dentre os quais alguns apresentam um papel predominantemente repressivo e outros uma função predominantemente hegemônica (ALTHUSSER, 1971: 145), ainda há um déficit de teoria de estado nas análises de Gramsci, déficit esse responsável pelo fato de a teoria da hegemonia gramsciana ter sido, até o momento, excepcionalmente utilizada em relação ao direito: o teórico voltou toda sua atenção às instituições culturais que organizam o consenso de massa, mas não às instituições políticas da democracia burguesa (ANDERSON, 1979: 39 ff.; mas cf. também PRIESTER op.cit.: 59 ff.). Porém, a partir de uma de suas afirmações sobre tais instituições, torna-se claro como se deve utilizar a teoria de Gramsci para analisar o aparelho de hegemonia do direito: na burocracia, o "corpo de funcionários da liderança" se cristaliza. Nos aparelhos político e jurídico, atua não só de forma repressiva, mas também de maneira hegemônica: “naturalmente, todos os três poderes são também órgãos de hegemonia política," mas em níveis diferentes: o parlamento é o que se encontra ligado de forma mais estreita à sociedade civil, o poder judiciário representa a continuidade da lei escrita (mesmo contra o governo), ao passo que o governo, no sentido técnico, é a forma mais repressiva de poder do Estado (GRAMSCI, ibid. §81: 773).

Antes de passarmos à aplicação da análise de Gramsci ao aparelho de hegemonia jurídica, devemos primeiramente analisar mais detidamente esse "corpo de funcionários da liderança”, visto que Gramsci o analisa sob o título de "intelectuais", trazendo 
juntamente com os conceitos de hegemonia e sociedade civil a terceira extensão conceitual. Pois a figura do intelectual em Gramsci é "menos a de um pensador contemplativo, no modo do velho estilo idealista da intelligentsia, do que a de um organizador [...]" (EAGLETON, 1991: 119) da hegemonia. Os intelectuais conduzem o processo catártico de desenvolvimento dos interesses particularistas em uma weltanschauung coerente (STAFF, 1989: 179). A hegemonia deve ser organizada, simplesmente porque a ideologia não é um reflexo automaticamente proveniente de fora das estruturas sociais. E tal organização cabe àqueles que, numa determinada sociedade, ocupam a posição de intelectuais dentro da divisão social do trabalho (GRAMSCI, 1991 ff., Q12§1: 1500). No feudalismo, os "clérigos ainda detinham o monopólio sobre as superestruturas": "a ideologia religiosa, i.e., a filosofia e a ciência da época, incluindo escolas, educação, moralidade, justiça, caridade, bem-estar etc." (ibid. 1498). Com a diferenciação dos diversos setores presentes nas sociedades capitalistas, essas posições sociais ficam dispersas entre os vários aparelhos de hegemonia. Na hierarquia do trabalho físico e mental, todas essas posições ficam do lado do trabalho mental: "o Estado encarna, na totalidade de seus aparelhos [...] o trabalho intelectual em sua separação do trabalho manual” (Poulantzas, 2001: 56).

Os intelectuais continuamente reajustam o equilíbrio das forças sociais e tornamse porta-vozes de um complicado sistema de alianças (DEMIROVIC, 1999: 23, 26), bem como funcionários das superestruturas (SASSOON, 1987: 138). Esse conceito de intelectual distancia-se da visão idealista acerca dos intelectuais como indivíduos aparentemente fora das relações sociais de poder e, portanto, desmitifica o trabalho intelectual como tal (ibid. 135 ff.). Em detrimento dos "grandes intelectuais", literatos e filósofos, Gramsci está mais preocupado com os intelectuais inferiores, os especialistas e os técnicos da hegemonia, os quais podem providenciar uma linguagem adequada a um estágio específico do desenvolvimento histórico. Se por meio disso eles conseguirem formar uma weltanschauung, poderão, desse modo, ser considerados "intelectuais orgânicos.” Suas ideias não são especulações subjetivas arbitrárias, mas devem ser capazes de articular amplas coalizões sociais de interesses (EAGLETON, 1991: 119).

\section{Direito hegemônico}

Gramsci insistiu na dinâmica intrínseca das superestruturas. O fenômeno do direito, em grande parte ignorado por ele e também por seus seguidores, exibe um "significado inerentemente normativo" de teor altamente específico (HABERMAS, 2004: 130) que o torna, em grande medida, exemplo paradigmático de uma infraestrutura substancial na organização da hegemonia. Esse significado inerente é o que dá ao direito seu valor agregado nas lutas hegemônicas, tornando impossível a representação reflexiva e direta das relações sociais de poder no direito. Essa questão é tomada tanto pela teoria jurídica materialista (BUCKEL, 2007) quanto pela teoria sistêmica 
do direito. Para essa última, as relações jurídicas acumulam-se em conjunto num sistema operacionalmente fechado, que se reproduz exclusivamente por meio de suas próprias operações (LUHMANN, 2004: 76). Isso é - em termos materialistas expressão do fato de que, em sociedades organizadas com base nos princípios capitalistas, as relações sociais são autonomizadas em face dos atores imediatos em formas sociais, criadas sem seu conhecimento. Elas são "as formas reificadas e fetichizadas, decifráveis apenas através de críticas teóricas adotadas pelas relações mútuas de indivíduos na sociedade, autonomizadas em face de sua vontade e ações conscientes, e as quais caracterizam suas percepções imediatas e orientações comportamentais: mercadoria, dinheiro, capital, direito, Estado" (HIRSCH, 1994: 161).

A diferenciação e a autonomização de subáreas sociais tornam essas relações sociais autorreferenciais. Comunicações jurídicas, voltadas ao código legal/ilegal, relacionam-se exclusivamente com comunicações jurídicas (LUHMANN, op.cit., 67), de modo que é o próprio direito, em última análise, que determina o que o direito é (FISCHER-LESCANO, 2006: 13).

Os conflitos hegemônicos ocorrem no ordenamento jurídico ou na forma jurídica sob as condições dessa autonomização autorreferencial: em processos judiciais. Estes constituem conjuntos de praxes e instituições: tribunais, regras de processo, normas jurídicas substanciais, doutrinas, pareceres versados e autodescrições acadêmicas, argumentação jurídica e sujeitos devidamente acostumados e ela, conhecimento jurídico, regras de temporização e especificidades arquitetônicas: “os sujeitos jurídicos estão, portanto, confinados ao domínio do direito" (Hunter, 2006: 40). Assim, o direito é, ao mesmo tempo, uma relação social congelada e opaca, bem como um adiamento, atrasando e dificultando a afirmação direta de reivindicações de poder por parte dos sistemas político e econômico (BUCKEL, 2007; FISCHER-LESCANO; CHRISTENSEN, 2005: 240).

Os intelectuais da área jurídica organizam o consenso hegemônico tendo em vista os pré-requisitos substanciais especiais da tecnologia jurídica. Eles controlam, na argumentação jurídica, uma tecnologia específica de conhecimento e organizam processos judiciais. Mas aqui, no direito, não são os grandes intelectuais e os filósofos jurídicos que contam, mas a prática cotidiana eficiente de intelectuais inferiores que, embora se mantenham mais estritamente aos critérios permitidos (DEMIROVIC, 1999: 26), são responsáveis, por meio de seus conhecimentos imanentes do ordenamento jurídico, pela organização da hegemonia na argumentação jurídica (doutrinas). Este é o quadro de referência essencial de várias normas e decisões que fixam no tempo soluções outrora encontradas e, assim, as torna reprodutíveis, estabelece valores legais, permite a sistematização e a diferenciação e, além disso, armazena diversas soluções padronizadas e conflitos.

A doutrina, concebida como a língua dos intelectuais jurídicos, cria um efeito especial aqui: fechando-se hermeticamente contra investigações (de política jurídica) 
contínuas e infindáveis, age como uma regra de impedimento em relação aos argumentos que buscam justificação (LUHMANN, 2004: 423). Ao afigurar-se como um processo imanente e puramente técnico, como uma necessidade jurídica (KENNEDY, 1997: 1 f.), torna a produção de hegemonia "invisível”, ou, nos termos de teoria sistêmica, o "paradoxo" do sistema jurídico é implementado pelo estabelecimento de paradas para reflexão. Aquilo que é estabelecido como sendo lei em condições históricas específicas não é determinado pelo sistema jurídico por si só, mas é o resultado de uma “weltanschauung” inscrita na lei, elaborada por intelectuais jurídicos. Os castelos do mundo do direito são erigidos em areia movediça. O paradoxo básico não pode incidir nas operações diárias do direito, visto que qualquer esforço semelhante sobre as fundações enfraqueceria a funcionalidade do direito e desmoronariam os castelos. Em vez disso, as operações do direito preocupam-se em tornar invisíveis as fundações instáveis, uma técnica elaborada pela dogmática e teoria jurídicas, uma vez que estas agem como se houvesse algum fundamento legítimo elementar para as diversas decisões (FISCHER-LESCANO, 2005: 21 f.).

Consequentemente, a hegemonia se torna significativa precisamente no ponto mais fraco do sistema jurídico, a alegação de frágil legitimidade de suas entidades jurídicas. Este é o ponto em que os intelectuais jurídicos têm de desenvolver uma argumentação hegemônica, i.e., aquela que formula um consenso, ainda que assimétrico, de natureza "ético-política", uma complexa "vontade coletiva", com base nas atuais relações de força. Para isso, as doutrinas oferecem uma espécie de infraestrutura para universalização e estandardização, isto é, para tornar compatíveis projetos hegemônicos inconciliáveis. Tanto a abstração quanto os procedimentos justificatórios formalizados oferecem, através das entidades jurídicas já estabelecidas - e da fixação, da sistematização e de sua reprodutibilidade -, um reservatório para a argumentação, que é, por conta disso, desvinculado de sua arbitrariedade em benefício de interesses particularistas através de uma espécie de restrição formal. As entidades jurídicas são produtos sedimentados, estrategicamente seletivos, de litígios passados. A argumentação que simplesmente ignorasse estes últimos ou se distanciasse deles sem qualquer empenho na justificação revelar-se-ia arbitrária. Em vez disso, deve-se utilizá-los e, assim, reproduzi-los simultaneamente, além de retirá-los do caminho.

Por um lado, as lutas hegemônicas são normalizadas através dessa restrição formal, mas, por outro, tal restrição lhes oferece uma ligação com a universalização e a compatibilização (cf. TEUBNER, 2001). Opiniões “dominantes" e de "minoria” refletem o estado atual do consenso hegemônico no direito em uma abertura sem igual. Frases genéricas como "política pública" ou "sistema de valor objetivo" são apenas substitutas disfarçadas para isso. Nesse sentido, a decisão judicial é um processo pelo qual relações sociais objetivas são articuladas numa semântica jurídica - e, portanto, alienada, especialmente codificada. Isto está longe da obscura suspeita de que a qualidade de uma decisão depende daquilo que os juízes comeram em seu desjejum. 
A weltanschauung assim expressa no direito também encontra seu caminho nas tecnologias de liderança através da forma específica do direito. Atribui-se grande importância à hegemonia jurídica. Pois em detrimento da visão de que o direito meramente sanciona as relações existentes, Gramsci considera que o direito é "na realidade uma luta pela criação de um novo costume” (Q6\$98: 791). O Estado, no sentido integral, empenha-se para criar e manter uma forma específica de coexistência e de relações individuais, a fim de fazer com que certos costumes e formas de conduta desapareçam, além de disseminar outros. É o direito (juntamente com, entre outros, as escolas) o meio para isso (Q13§11: 1548). Se a liderança política tem de criar um conformismo social, então realmente é o "problema jurídico" "educar” as “massas” (Q6§84: 777), ou “um assunto para o 'direito',", através do qual "a pressão educativa sobre os indivíduos é exercida, de modo a conseguir o consenso e a colaboração destes" (Q13§7: 1544). Isso não representa um "conceito de controle" tradicional e político, mas "o caráter educativo, criativo e formativo do direito" (Q6§98: 792) como uma forma produtiva de poder, definindo por meio de práticas legais tipos de subjetividade, formas de conhecimento e, desse modo, também criando relações entre seres humanos e a verdade (FOUCAULT, 2001): subjetividades e formas de vidas.

Tal efeito somente pode ser produzido pelo direito se este for entendido de forma similar num sentido mais amplo: como um aspecto do Estado, no sentido mais estrito, assim como da sociedade civil. A atividade do direito é mais extensa do que a prática do Estado simplesmente, agindo com o apoio do monopólio da violência. Do ponto de vista da codificação e da implementação, pertence às tarefas do Estado num sentido restrito, e, nessa medida, também possui um caráter repressivo. A prática jurídica, no entanto, gera entre os sujeitos uma concepção específica sobre a maneira correta de viver, sobre o que é o direito (KRAMER, 1975: 94), autorizando, por conseguinte, uma forma peculiar de vida (LITOWITZ, 2000: 530): “A 'face dupla do direito', consensual e coerciva, constitui uma dialética específica da concepção burguesa de direito, a qual Gramsci pressupõe ser uma concepção ética” (CUTLER, 2005: 529). A “concepção ética" aqui discutida refere-se ao estímulo de autotecnologias, a elaboração de uma forma de relação consigo próprio que possibilite ao indivíduo se constituir enquanto sujeito de um modo de vida específico.

Os litígios jurídicos, por conseguinte, sempre dizem respeito à implementação de uma weltanschauung em especial, sob a forma de prática de vida, de "direito de vida" (na tradição do direito livre: EHRLICH, 1913: 390), que novamente aponta para a materialidade do ideológico. As normas jurídicas são, portanto, formas complexas de "vinculação ao tempo": a fim de que as práticas sociais possam ser repetidas, para se unirem umas às outras, as expectativas normativas precisam ser estabilizadas, mesmo (e especialmente) no caso onde alguém age diferentemente do esperado (LUHMANN, 2004: 142). 


\section{UM NOVO “BLOCO HISTÓRICO”: DIREITO GLOBAL FRAGMENTADO}

Para Gramsci, o direito hegemônico é, à luz de tudo isso, o oposto do direito sujeito à imposição arbitrária, carecendo até mesmo dos pré-requisitos mínimos para legitimidade. Em contraste com o debate conduzido no direito internacional sobre o chamado "direito hegemônico" (HESS, 2005; KRISCH, 2004; BYERS; NOLTE, 2003; VAGTS, 2001) - que bem poderia se beneficiar da elucidação provida pela teoria da hegemonia - o direito hegemônico constitui, para Gramsci, a parte do "direito integral" que pode dispensar as armas do aparelho governamental do Estado-nação, porque conta com um clima de amplo reconhecimento da sociedade.

A forma que o direito hegemônico toma sob determinadas condições sociais depende do "bloco histórico" em que é unido com outras praxes sociais. Por conta disso, Gramsci indica um conjunto especial de relações das forças sociais em que as várias relações jurídicas, políticas e ideológicas estão incorporadas e organicamente ligadas umas às outras, como uma unidade compacta, incluindo o pensamento e o sentimento de um modo de vida coletivo que abrangem todas as diversas forças (DEMIROVIC, 2001: 61). O "bloco histórico" é, pois, todo o conjunto de forças materiais (conteúdo) e ideologias (forma), no qual "as ideologias seriam caprichos individuais sem as forças materiais" (Q7§21: 877). ${ }^{4}$

\section{I Transnacionalização}

O "fordismo" foi o exemplo analisado por Gramsci enquanto tipo ideal dessa espécie de bloco histórico (Q9\$72: 1128 ff.). Começou a ganhar forma da década de $1930 \mathrm{em}$ diante, nas metrópoles do norte ocidental, e baseava-se essencialmente numa reorganização taylorista do processo de trabalho e na combinação da produção em massa com o consumo de massa, o crescimento econômico, o pleno emprego, o consenso assimétrico entre capital, sindicatos e Estado juntamente com um modelo baseado na ideia do homem como provedor do sustento da família. Além disso, foi acompanhado por um Estado de bem-estar social burocrático keynesiano e uma subjetividade disciplinada (BUCKEL, 2006). Quando essa formação entrou em crise em meados da década de 1970, aspectos de um novo bloco histórico lentamente começam a se formar, tais como uma economia baseada no conhecimento, uma produção flexível e transnacional e a transformação do Estado de bem-estar social, em que a segurança social é subordinada aos imperativos da competição. Esses são os resultados de um processo de busca, em que forças sociais específicas foram capazes de prevalecer.

No âmbito do novo bloco histórico emergente (denominado pós-fordismo, pósmodernidade ou neoliberalismo), os processos jurídicos também se ganham um caráter transnacional, juntamente com as relações de poder. Particularmente na década de 1990, os aparelhos de hegemonia jurídica global foram formados (como os tribunais penais para a Iugoslávia e Ruanda - ICTY e ICTR - ou o Tribunal Penal Internacional - TPI - e o Tribunal Permanente de Revisão do MERCOSUL) ou obtiveram um novo 
caráter (a Corte Europeia de Justiça, as Cortes Europeia, Interamericana e Africana de Direitos Humanos e o Painel de Resolução de Disputas da OMC). Atualmente, cento e vinte e cinco órgãos internacionais de tomada de decisão são listados pelo Projeto de Cortes e Tribunais Internacionais (PCTI) ${ }^{5}$ De forma similar, os tribunais nacionais foram trazidos de maneira mais intensa a esse sistema heterárquico de "remédios globais" (FISCHER-LESCANO, 2005: 175 ff.), em que são tratadas questões jurídicas transnacionais do direito penal internacional para reivindicações de restituição, oriundas da violação dos direitos humanos em todo o mundo. Esses variados aparelhos de hegemonia fazem parte de uma rede juridicamente pluralista onde "várias ordens jurídicas operam de forma subnacional, nacional, regional e transnacional, sobrepondo-se e cruzando-se (CUTLER, 2005: 535). Essa foi a mudança decisiva ocorrida no sistema jurídico fordista.

Embora a descrição gramsciana acerca do "bloco histórico" e das relações de poder nele materializadas tenha permanecido estritamente dualista devido ao foco de Gramsci no Fordismo, e esse teórico tenha separado analiticamente as relações de poder interestatais das intraestatais, percebendo a ligação existente entre as duas dimensões como incorporação das relações de poder interestatais no bloco intraestatal e vice-versa, ${ }^{6}$ análises político-científicas, feitas a partir de uma perspectiva de neogramsciana, têm estendido o dualismo de Gramsci a uma dimensão global ${ }^{7}$ no decurso dos debates sobre a constitutionalização de uma ordem mundial neoliberal e a transnacionalização de complexos regulatórios.

Assim, litígios hegemônicos não precisam mais ser puramente orientados nacional e internacionalmente, mas podem também ser globais. Essas formas globais políticas são geradas nos movimentos ligados em rede, nas ONGs, nas associações profissionais, na mídia, nos sindicatos e em outros grupos de interesse, que, na era da Internet, fazem uso dos meios de comunicação de abrangência mundial. Mesmo se a competitividade global e a eficiência econômica tenham se tornado, desde então, discursivamente hegemônicas e ajam aparentemente como "normas fundamentais [grundnorms] de um bloco histórico cada vez mais transnacional” (CUTLER, 2005: 535), não obstante os projetos anti-hegemônicos estarem presentes, nomeadamente como lutas por reconhecimento de natureza ambientalista, feminista, ativista pela saúde, relacionadas ao risco da tecnologia, às políticas educacionais, aos direitos humanos etc. De forma advocatória, estas também estão adotando uma problemática global que Luhmann nomeou "exclusão total," a qual, em relação a situações de exploração específica de classe, contém a radicalização que, nas zonas de exclusão das favelas globais, tudo o que importa é a própria sobrevivência do indivíduo, e onde mesmo a exploração com o mínimo de provisão material parece ser uma condição luxuosa inalcançável (1997: 631 ff.). Os "exemplos do surgimento de um cosmopolitismo subalterno que apresenta ligação diretamente com o campo dos direitos humanos," recolhidos por Boaventura de Sousa Santos (2002: 285), voltado a um 
projeto de inclusão por meio dos direitos humanos, demonstra que "políticas contrahegemônicas de direitos humanos" globais (ibid. 281) começam a atrair atenção global a tais situações radicais de exclusão.

\subsection{TÉCNICAS CONTRA-HEGEMÔNICAS}

Enquanto a perspectiva gramsciana se concentra nas relações hegemônicas no direito global, o debate sobre a hegemonia do direito internacional inicia-se a partir da análise de Carl Schmitt que defende que "aqueles com verdadeiro poder também podem definir conceitos e palavras por si mesmos. Caesar dominus et supra grammaticam: César também é senhor da gramática” (SCHMITT, 1932: 202). Entretanto, numa "hegemonia" gramsciana "como legislatura de todos," a ideia de ser capaz de controlar processos de significação social pelo mundo nada mais é do que a fantasia do Príncipe de Maquiavel, ${ }^{8}$ i.e. uma tecnologia de poder pré-moderna suplantada, um "soberanismo" que foi "o sonho mais antigo do mais remoto soberano": "nenhum de meus súditos me escapa, e nenhum gesto de qualquer um de meus súditos permanece desconhecido para mim" (FOUCAULT, 2004: 103). Tanto o modelo maquiavélico como o clausewitziano presentes na teoria de direito internacional, onde, segundo Schmitt, o direito é considerado como a continuação de política por outros meios (para uma apreciação crítica, ver FISCHER-LESCANO; LISTE, 2005), subestimam a intratabilidade dos procedimentos específicos da tecnologia jurídica e a complexidade da formação da hegemonia.

As decisões jurídicas não são simplesmente disfarces políticos. O direito segue uma lógica própria e possui seus próprios programas e códigos, em que as contradições sociais podem ser simultaneamente compatibilizadas e dissimuladas. A politização, no sentido de manifestação do aspecto genuinamente político do direito, é, desde o início, confrontada pela dificuldade em decifrar, por atrás do contexto técnico, a resolução dos conflitos sociais através do combate (cf. SKORDAS, 2007). Consequentemente, esse compromisso foi escolhido pelo CLS como sendo sua prática jurídica central, a fim de alterar a forma existente de divisão social do trabalho, submetendo os intelectuais do direito a procedimentos democraticamente regulamentados para "produzir" o direito. Pois se os projetos hegemônicos se desenvolvem no âmbito do direito, se a política ocorre na situação de tomada de decisão, então isso precisa ser democratizado.

Mas a perspectiva gramsciana requer uma estratégia emancipatória mais abrangente: uma vez que se tenha reconhecido que os litígios jurídicos se preocupam não apenas com o caso individual, mas com a execução de uma weltanschauung hegemônica sob a forma de prática vivida, que os aparelhos jurídicos de hegemonia elaboram um senso comum que se encarrega de regular as subjetividades e as formas de vida, sobrevém a ideia de que a questão essencial é adotar a luta pelo direito (global) como parte da luta pela transformação emancipatória da sociedade mundial, e impedir que 
o direito da sociedade mundial seja administrado exclusivamente nos quintais e nos fundos de procedimentos de governança globais não transparentes. O movimento operário globalizado, os ativistas ambientais, as feministas, o novo movimento global de Seattle a Gênova consequentemente constituem, nesse sentido, "um movimento e um processo que apresenta uma forma múltipla e capilar que combina entendimentos foucaultianos e gramscianos acerca do poder e da hegemonia. Na qualidade de um movimento ético e político, eles formam um "Príncipe pós-moderno", isto é, uma nova forma global de agência política coletiva” (GILL, 2002: 51). Isso tenta desenvolver uma vontade coletiva, i.e. "tornar-se um Estado," no sentido amplo de desenvolver uma nova visão de mundo, inscrita, de maneira não menos importante, no direito. O direito, enquanto uma infraestrutura material para a organização da hegemonia, segue aqui sua própria infraestrutura de comunicação estrategicamente seletiva, acessível não de forma direta, mas somente mediada através dos funcionários da superestruturas, mas, por essa mesma razão, também bloqueando a ação direta de interesses poderosos.

A introdução juridicamente criativa de um estilo de vida alternativo pelo novo movimento global pode, caso se engaje na necessidade de universalização pela forma jurídica obrigatória, ser interpretada como a dimensão social da produção legislativa: por meio da escandalização, da criação de slogans e de incessantes exigências uma reminiscência do conceito de colère publique de Emile Durkheim (DURKHEIM, 1930: 153) - (LUHMANN, 1995: 229; TEUBNER, 1996). Nesse sentido, essa exigência por um "direito global incipiente", destacando os males como escandalosos, estabelecendo redes de atividade com ONGs e advogados de vítimas, intervindo em processos jurídicos (como terceiro interessado) e a negociação de convenções governamentais (sendo o exemplo mais recente os estatutos do TPI), não é um projeto impossível a princípio. Em vez disso, a luta pela hegemonia no direito global aponta questões em muitas arenas do direito global onde movimentos sociais juridicamente criativos, num sentindo gramsciano, podem atuar, "incluindo aqueles voltados à responsabilização corporativa por violações ambientais e de direitos humanos, bem como movimentos voltados a questões únicas, tais como aquelas para banir minas terrestres antipessoal, tentando criar o consentimento da população para caminhos alternativos de desenvolvimento sustentável, paz ou democracia (RAJAGOPAL, 2003: 18). E, embora tais movimentos careçam da cobertura do governo por meio do monopólio da força, eles são extremamente eficazes, haja vista que, do ponto de vista gramsciano, é "plausível argumentar que no direito internacional e nas relações internacionais, as condições sob as quais 'o consentimento espontâneo' pode ser fabricado são tão importantes, se não mais importantes, do que a existência de mecanismos enérgicos de execução" (ibid.), precisamente porque a questão é a formação de uma visão de mundo, a qual é tudo o que pode criar um consenso na utilização daquele monopólio da força em primeiro lugar. 
As técnicas contra-hegemônicas podem, nesse caso - como um dos aspectos de uma estratégia mais abrangente - escapar das tendências existentes de criação jurídica. Para tanto, será necessário, contudo, criar, no próprio direito global, condições para um arcabouço estrutural para a receptividade social do mundo, i.e. implementar mecanismos que unam organizações eficazes e organizadas, associações profissionais, juízes, mídia, imprensa, empresas transnacionais e movimentos com os respectivos públicos próprios de seu contexto funcional, de tal modo que a decisão esteja ligada à discussão e, portanto, uma autonomização antidemocrática irrestrita dos aparelhos da economia, da tecnologia, da ciência, da arte, da religião possa ser contestada. ${ }^{9}$ Aqui, o debate em curso sobre a constitucionalização no direito global contém o potencial para inscrever a lógica contra-hegemônica nos aparelhos. "O uso do vocabulário constitucional - como o juízo estético de Kant - transforma o sofrimento individual num mal objetivo que aflige não apenas a vítima, mas todos" (KOSKENNIEMI, 2007: 35). Particularmente, a luta para expandir os direitos de ação processualmente garantidos a fim de implementar os direitos humanos é necessária (sobre o assunto, ver ALTER, 2006). O objetivo geral deve ser converter os princípios decorativos em direitos obrigatórios e tornar as cortes espalhadas pelo mundo locais de protesto contra-hegemônico (LOBEL, 2004).

A concepção predominante de "hegemonia" presente o direito não tem olhos para esses argumentos, para as estratégias contra-hegemônicas e para os processos emancipatórios de escandalização, mas se concentra nos efeitos jurídicos das tentativas dos aparelhos governamentais nacionais de impor interesses corporativos não de forma hegemônica, mas apenas por meio da força militar autonomizada. Faz parte da ironia presente no conceito de hegemonia assim promovido que no próprio ato de crítica às pretensões jurídicas imperiais enquanto "direito hegemônico" que os intelectuais jurídicos (internacionais) se submetam a esse mesmo direito, reconhecendo seu status como “direito" e atribuindo aos fenômenos de tentativa de autolegitimação dos aparelhos globalmente operantes a tonalidade de uma validade de toda a sociedade por meio do uso do adjetivo "hegemônico". A partir de Gramsci, pode-se agora insistir contrafatualmente que quem ignora o lei pode muito bem ser capaz de cobrir o mundo com bombas, mas eles se posicionam à margem do lei. A "indignação" mundial "em relação a grandes violações dos direitos humanos e infrações manifestas da proibição de atos de agressão militar" (HABERMAS, 2004: 142) mostra que a ação direta para estabilização transnacional das expectativas jurídicas tem sido afastada dos aparelhos militares. As relações hegemônicas de poder determinarão se eles estão preparados para suportar as violações de direitos através de crimes de guerra, tortura, guerras agressivas etc. sem consequências, senão a ideologia jurídica futuramente "punirá como atividade criminosa (e, de forma original, deixando a 'opinião pública' agir como um elemento sancionador)" (GRAMSCI, 1991 ff., Q13§11, 1549) tais atos, mesmo nos casos onde os responsáveis estejam agindo em nome dos aparelhos militares e policias do noroeste. 
Qual visão de mundo, na luta pela globalização jurídica hegemônica enquanto uma luta de libertação por uma ordem mundial justa, crescerá para se tornar a "opinião prevalecente”, um princípio geral de direito ou até mesmo uma lei obrigatório não está à disposição dos aparelhos executivos militares e policiais. Em vez disso, nos conflitos normativos na escala da sociedade mundial, o que irá decidir entre direitos iguais, quando um direito global se opõe a outro, será a força: a força da hegemonia global.

: ARTIGO APROVADO (09/01/2009) : RECEBIDO EM 11/10/2008

NOTAS

* Gostaríamos de agradecer Stephan Adolphs, Regina-Maria Dackweiler, Günter Frankenberg, Felix Hanschmann, Gunther Teubner, Rudolph Wiethölter e Jens Wissel pelas críticas construtivas.

1 "Há, portanto, uma antinomia aqui: direito contra direito, ambos igualmente marcados pela lei de troca de mercadorias. Entre direitos iguais, a força decide. Assim, na história da produção capitalista, a estandardização do dia de trabalho assume a forma de uma luta ao longo dos limites do dia de trabalho - uma luta entre o capitalismo universal, i.e. a classe capitalista, e o trabalhador universal, ou a classe trabalhadora” (MEW, 23: 249; cf. também Miéville, 2005).

2 Sobre a situação da discussão teórico-jurídica de Gramsci, ver, entre outros, Cutler 2005, Litowitz 2000, Staff 1989, Cain 1983, Benney 1983, Kennedy 1982, Greer 1982, Sumner 1979: 257 ff.

3 Sobre as diferenças existentes entre as abordagens kantiana e pós-moderna, o estudo de Seibert 2006 possui um caráter bastante instrutivo; para uma visão geral da teoria jurídica feminista, ver Elsuni, 2006; Hunter, 2006.

4 Em relação ao sistema ideológico do direito, Hans Kelsen o formula de forma muito similar quando escreve que, “na verdade, apenas aquelas normas jurídicas cujos conceitos são eficazes podem ser consideradas supostamente válidas [...] O conteúdo dos dois sistemas [direito e natureza (Kelsen) - direito e relações de poder (Gramsci), S.B. \& A.F.L.] não coincide completamente, nem diverge totalmente. A tensão não deve exceder um limite máximo - pois, nesse caso, a suposição de um sistema jurídico intrínseco do "direito" perderia sentido - nem deve ficar abaixo do um limite mínimo - uma vez que qualquer possibilidade de usar o sistema de direito como esquema interpretativo ou avaliativo útil da conduta real do homem [...] seria afastada." (Kelsen 1925: 18; idem 1932: 98 f.: "Que o direito no sentido objetivo, i.e. a ordem jurídica, seja a vontade do Estado não implica a ideia de que o Estado "produz" o direito, mas, sim, que este é o portador de tal ordem, cujo conteúdo é "produzido" por um processo social [...].”)

5 Disponível em: <www.pict-pcti.org $>$.

6 "Dever-se ainda ter em mente que as relações internacionais se entrelaçam com essas relações internas do Estadonação, gerando, portanto, novas combinações originais e historicamente específicas (Gramsci, 1992 ff.: Q13§17, 1561).

7 Cf. Bieling, Brand and Geis; Wolff in: Buckel; Fischer-Lescano, 2007.

8 Gramsci: “O Príncipe moderno, o mito do Príncipe, não pode ser uma pessoal real, um indivíduo verdadeiro; ele só pode ser um organismo, um elemento social complexo em que uma vontade coletiva já começa a se concretizar, que é reconhecida e se afirmou, em parte, na ação.” (Q13§1, 1537). 
9 Sobre a relação entre discussão e decisão como acoplamento estrutural, cf. Brunkhorst, 2002a, 676, FN 6; e, em detalhes, idem 2005.

\section{REFERÊNCIAS BIBLIOGRÁFICAS}

Alter, Karen J. (2006): »Private Litigants and the New International Courts«, in: Comparative Political Studies 39, 22-49.

Althusser, Louis (1971): »Ideology and Ideological State Apparatuses. Notes Toward an Investigation«, in: Lenin and Philosophy and others Essays, New York and London, 127-188.

Becker, Dietrich Claus (2005): Von Namen und Nummern: Kollisionen unverträglicher Rechtsmassen im Internet. BadenBaden.

Benney, Mark (1983): »Gramsci on Law, Morality, and Power«, in: International Journal of the Sociology of Law 11, 191-208.

Brunkhorst, Hauke (2002): „Globalising Democracy Without a State: Weak Public, Strong Public, Global Constitutionalism《, in: Millennium 31, 675-690.

(2005): Solidarity: From Civic Friendship to a Global Legal Community, Cambridge, Mass.

Buci-Glucksmann, Christine (1980): Gramsci and the State. London.

Buckel, Sonja (2006). »Post-Fordism«, in: Austin Harrington/Barbara Marshall/Hans-Peter Müller (Hg.) Encyclopedia of Social Theory. London/New York, 448-449.

(2007): Subjektivierung \& Kohäsion. Zur Rekonstruktion einer materialistischen Theorie des Rechts. Weilerswist. ; Fischer-Lescano, Andreas (2007). 'Hegemonie gepanzert mit Zwang'. Zivilgesellschaft und Politik im Staatsverständnis von Antonio Gramsci. Baden-Baden.

Byers, Michael/Nolte, Georg (Hg., 2003): United States Hegemony and the Foundations of International Law. Cambridge.

Cain, Maureen (1983): »Gramsci, The State and the Place of Law«, in: David Sugarman (ed.), Legality, Ideology and the State. London: 95-117.

Cutler, A. Claire (2005): „Gramsci, Law, and the Culture of Global Capitalism«, in: Critical Review of International Social and Political Philosophy 8(4), 527-542.

Demirovic, Alex (1999): Der nonkonformistische Intellektuelle. Die Entwicklung der Kritischen Theorie zur Frankfurter Schule. Frankfurt am Main. (2001): »Hegemoniale Projekte und die Rolle der Intellektuellen«, in: Das Argument, Zeitschrift für Philosophie und Sozialwissenschaften (239), 59-65.

Derrida, Jacques (1990): »Force of Law: The ^Mystical Foundation of Authority««, in: Cardozo Law Review 11:4, 924-1045.

Eagleton, Terry (1991): Ideology. An Introduction. London/ New York.

Ehrlich, Eugen (1913): Grundlegung der Soziologie des Rechts. München.

Elsuni, Sarah (2006): »Feministische Rechtstheorie«, in: Sonja Buckel/Ralph Christensen/Andreas Fischer-

Lescano (eds). Neue Theorien des Rechts. 163-186.

Esser, Josef (1970): Vorverständnis und Methodenwahl in der Rechtsfindung. Rationalitätsgrundlagen richterlicher Entscheidungspraxis. Kronberg/Ts.

Fischer-Lescano, Andreas (2005): Globalverfassung. Die Geltungsbegründung der Menschenrechte. Weilerswist. (2006) »Global Constitutional Struggles: Human Rights between colère publique and colère politique«, in: Wolfgang Kaleck/Michael Ratner/Tobias Singelnstein \& Peter Weiss (eds.), International Prosecution of Human Rights Crimes, New York, 13-29.

; Christensen, Ralph (2005): »Auctoritatis interpositio. Die Dekonstruktion des Dezisionismus durch die Systemtheorie«, in: Der Staat. Zeitschrift für Staatslehre und Verfassungsgeschichte, deutsches und europäisches öffentliches Recht (2), 213-241.

; Liste Philip (2005): \V̈̈lkerrechtspolitik. Zu Trennung und Verknüpfung von Politik und Recht der Weltgesellschaft«, in: Zeitschrift für Internationale Beziehungen 12:2, 209-249.

; Teubner, Gunther (2004): »Regime-Collisions: The Vain Search for Legal Unity in the Fragmentation of Global Law «, in: Michigan Journal of International Law 25, 999-1046.

Foucault, Michel (1990\}): The History of Sexuality: An Introduction.Vol. 1, New York. 
; (2001): Michel Foucault, »Truth and Judicial Forms« (1974), in Essential Works of Foucault 1954-1984,Vol. III (Power), translated by Robert Hurley, 1-15.

; (2004): Geschichte der Gouvernementalität I. Sicherheit, Territorium, Bevölkerung.Vorlesung am Collège de France 1977-1978. Frankfurt am Main.

Frankenberg, Günter (2006): »Partisanen der Rechtskritik. Critical Legal Studies etc.«, in: Sonja Buckel/Ralph Christensen/Andreas Fischer-Lescano (eds). Neue Theorien des Rechts. Stuttgart, 97-116.

Fraser, Nancy (2003): »Soziale Gerechtigkeit im Zeitalter der Identitätspolitik«, in: Nancy Fraser/Axel Honneth, Umverteilung oder Anerkennung? Frankfurt am Main, 13-128.

Gill, Stephen (2002): »Constitutionalizing Inequality and the Clash of Globalizations«, in: International Studies Review 4, 47-65.

Gramsci, Antonio (1991 ff.): Gefängnishefte. Kritische Gesamtausgabe. Ed. Klaus Bochmann/Wolfgang Fritz Haug. Hamburg/Berlin. [The Notebooks ( $\mathrm{Q}=$ Quaderni del Carcere) 1-8 are published in English: Prison Notebooks, Volume 1-3. Editor: Joseph A. Buttigieg. New York, 1991-2007]

Greer, Edward (1982): »Antonio Gramsci and \Legal Hegemony«, in: David Kairys (ed.), The Politics of Law, New York 1982, 304-309.

Habermas, Jürgen (2004): »Hat die Konstitutionalisierung des Völkerrechts noch eine Chance?«, in: idem, Der gespalteneWesten. Kleine politische Schriften X. Frankfurt Main, 113-193.

Hess, Burkhard (2005): »Aktuelle Brennpunkte des transatlantischen Justizkonflikts«, in: Die Aktiengesellschaft, 897-905. Hirsch, Joachim (1994): »Politische Form, politische Institutionen und Staat«, in: Josef Esser/Christoph Görg/Joachim Hirsch (eds). Politik, Institutionen und Staat. Hamburg, 157-212.

Hunter, Rosemary (2006): »Law's (Masculine) Violence: Reshaping Jurisprudence«, in: Law and Critique 17 (Spring 2006), 27-46.

Hutchinson, Allan C./Monahan, Patrick J. (1984): »Law, Politics, and the Critical Legal Scholars: The Unfolding Drama of American Legal Thought«, in: Stanford Law Review 36, 199-245.

Jessop, Bob (1990): State theory. Putting the Capitalist State in its Place. Cambridge et al.

Kant, Immanuel (1967 \{1795\}): »Schrift zum ewigen Frieden«, Werkausgabe (ed. Wilhelm Weischedel), Bd. XI. Frankfurt am Main, 191-251.

Kelsen, Hans (1925): Allgemeine Staatslehre. Berlin (Nachdruck 1966). (1932): Hauptprobleme der Staatsrechtslehre. Tübingen.

Kennedy, Duncan (1997): A Critique of Adjudication. Cambridge Mass. (1982): »Antonio Gramsci and the Legal System«, ALSA Forum 6, 32-37.

Koskenniemi, Martti (2005): »Global Legal Pluralism. Multiple Regimes and Multiple Modes of Thought«, lecture, Harvard March 2005, available at: http://www.valt.helsinki.fi/blogs/eci/PluralismHarvard.pdf (2007): »Constitutionalism as a Mindset: Reflections on Kantian Themes about International Law and

Globalisation «, Theoretical Inquiries in Law 8, 9-36

Kramer, Annegret (1975): »Gramscis Interpretation des Marxismus«, in: Hans-Georg Backhaus (ed.). Gesellschaft. Beiträge zur Marxschen Theorie 4. Frankfurt am Main.

Krisch, Nico (2004): »Amerikanische Hegemonie und liberale Revolution im Völkerrecht«, in: Der Staat. Zeitschrift für Staatslehre und Verfassungsgeschichte, deutsches und europäisches öffentliches Recht 43:2, 267-298. Laclau, Ernesto/Mouffe, Chantal (2001): Hegemony and Socialist Strategy. Towards a Radical Democratic Politics. $2^{\text {nd }}$ ed. London.

Litowitz, Douglas (2000): »Gramsci, Hegemony, and the Law«, in: Brigham Young University Law Review (2), 515-551. Lobel, Jules (2004): »Courts as Forums for Protest«, in: UCLA Law Review 52, 477-561.

Luhmann, Niklas (1995): »Das Paradox der Menschenrechte und drei Formen seiner Entfaltung«, in: idem: Soziologische Aufklärung 6: Die Soziologie und der Mensch. Opladen, 229-236. (1997): Die Gesellschaft der Gesellschaft. Frankfurt am Main. (2004): Law as a Social System. Oxford.

Marx, Karl/Engels, Friedrich (1958): Marx-Engels-Werke. Bd. 1 - 40 (cit. as MEW). Berlin. Maus, Ingeborg (1992): »Zur Theorie der Institutionalisierung bei Kant«, in: eadem, Zur Aufklärung der Demokratietheorie: rechts- und demokratietheoretische Überlegungen im Anschluss an Kant. Frankfurt am Main. Miéville, China (2005): Between Equal Rights. A Marxist Theory of International Law. Leiden etc.

Paulus, Andreas L. (2004): »The War against Iraq and the Future of International Law: Hegemony or Pluralism?«, in: Michigan Journal of International Law 25, 691-733.

Poulantzas, Nicos (2001): State, Power, Socialism, London.

Priester, Karin (1981): Studien zur Staatstheorie des italienischen Marxismus: Gramsci und Della Volpe. Frankfurt/Main etc. Rajagopal, Balakrishnan (2003): International Law from Below. Development, Social Movements and Third World Resistance, Cambridge. 
Santos, Boaventura de Sousa (2002): Toward a New Legal Common Sense. Law, Globalization and Emancipation, $2^{\text {nd }}$ ed. London.

Sassoon, Anne Showstack (1987): Gramsci's politics. London.

Seibert, Thomas (2006): »Dekonstruktion der Gerechtigkeit: Nietzsche/Derrida«, in: Sonja Buckel/Ralph Christensen/Andreas Fischer-Lescano (eds). Neue Theorien des Rechts. Stuttgart, 29-56.

Skordas, Achilles (2007): »Just Peace Revisited «, in: Stephan Stetter (ed.), Territorial Conflicts in World Society. Modern Systems Theory, International Relations and Conflict Studies, London, 319-369.

Staff, Ilse (1989): »Kleine Anmerkung zum >Großen Intellektuellen««, in: Kritische Justiz 22(2), 176-183.

Sumner, Colin (1979): Reading Ideologies: an Investigation into the Marxist Theory of Ideology and Law. London.

Teubner, Gunther (1989): Recht als autopoietisches System. Frankfurt am Main.

(1996): »Global Bukowina: Legal Pluralism in the World-Society«, in: Gunther Teubner (ed.), Global Law

Without A State, London, 3-28.

(2001): »Alienating Justice: On the Social Surplus Value of the Twelfth Camel «, in: David Nelken and

Jirí Pribán (eds.), Law's New Boundaries: Consequences of Legal Autopoiesis, Aldershot, 21-44.

Vagts, Detlev F. (2001): »Hegemonic International Law«, in: American Journal of International Law 95:4, 843-848.

Wiethölter, Rudolf (1968): Rechtswissenschaft. Frankfurt a.M.

(1977): »Begriffs- und Interessenjurisprudenz - falsche Fronten im IPR und Wirtschaftsverfassungsrecht.

Bemerkungen zur selbstgerechten Kollisionsnorm«, in: Alexander Lüderitz/Jochen Schröder (eds). Internationales

Privatrecht und Rechtsvergleichung im Ausgang des 20. Jahrhunderts. Bewahrung oder Wende? Festschrift für Gerhard Kegel.

Frankfurt am Main, 213-263.

Wissel, Jens (2007): »Kräfteverhältnisse«, in: Wolfgang Fritz Haug (ed.). Historisch Kritisches Wörterbuch des

Marxismus. Hamburg (forthcoming).

Sonja Buckel

Senckenberganlage 26

60325

Frankfurt am Main - Alemanha

s.buckeldasoz.uni-frankfurt.de

Fachbereich Rechtswissenschaft

Bremen - Alemanha

fischer.lescanoluni-bremen.de
DOUTORA EM FILOSOFIA

Professora do Departamento de CIÊnCIAs Socials Johann Wolfgang-Goethe, Universidade dE FrankFuRT

Professora VISITANTE NA UnIVERSIDADE DE FLENSBURG

\section{Andreas Fischer-Lescano}

Consultor acadêmico do Instituto de Direito Público, UNIVERSIDADE DE FRANKFURT

Professor dA Universidade de Bremen 